\title{
MEASURING THE TURBULENT CHARACTERISTICS IN AN OPEN CHANNEL USING THE PIV METHOD
}

\author{
G.I. PECHLIVANIDIS ${ }^{1, *}$ \\ E. KERAMARIS ${ }^{1}$ \\ I.G. PECHLIVANIDIS ${ }^{2}$ \\ G.A. SAMARAS ${ }^{1}$
}

Received: $10 / 05 / 12$

Accepted: 27/07/12

\author{
${ }^{1}$ Alexander Technological Educational Institute of Thessaloniki \\ Department of Civil Infrastructure Engineering \\ Thessaloniki, Greece \\ ${ }^{2}$ School of Geology, Environment and Earth Sciences \\ Victoria University of Wellington, Kelburn, Wellington, New Zealand
}

\begin{abstract}
Investigation of open channel flows is very important for a wide range of applications, including restoration and enhancement of river aquatic systems. As a result, the scientific community has focused on providing further insights on the flow characteristics in vegetated channels. Vegetation may be submerged or emerged, rigid or flexible with high or low density. For rigid vegetation, the hydraulic behaviour of the channel is similar to the behaviour of a channel with macro-roughness which could be caused by the presence of geometrical elements (e.g. cylinders, cubes). For flexible vegetation, both the flexibility of the vegetation and the hydrodynamic of the flow contribute to the generation of several formations such as erect, gently swaying, and prone.
\end{abstract}

In this study, the characteristics of turbulent flow in an open channel were studied experimentally using Particle Image Velocimetry (PIV). This method assumes that the particles of a fluid faithfully follow the flow dynamics, hence the motion of these seeding particles are used to calculate velocity information of the flow. The experiments were conducted for both impermeable and permeable beds in a channel of $6.5 \mathrm{~m}$ length, $7.5 \mathrm{~cm}$ width and $25 \mathrm{~cm}$ height. Two grass-like vegetation types of different height $(2$ and $6 \mathrm{~cm}$ ) were used to represent permeable beds. These conditions are typical of flows encountered in sediment transport problems. Hydraulic characteristics such as distributions of velocities, turbulent intensities and Reynolds stress are investigated at a fine resolution using the PIV. Velocity is measured above the vegetation at different heights. Results show that velocity over the vegetation region is a function of the vegetation height and the total flow depth; velocity decreases as the vegetation height increases. In addition, we show that velocities above the vegetation region are much lower than velocities above an impermeable bed. This is due to the turbulent shear stresses and the existence of turbulence in the vegetation region, which reduce the mean velocity above the vegetation region. In addition, results show a region of zero velocity; between 3 and $6 \mathrm{~cm}$ and 1 and $2 \mathrm{~cm}$ for $a \mathrm{~cm}$ and $2 \mathrm{~cm}$ vegetation. This result shows that $50 \%$ of the vegetation behaves like an impermeable bed.

KEYWORDS: Open channel flow, Particle Image Velocimetry, Experimental analysis, Turbulent flow, Permeable bed, Vegetation, Impermeable bed.

\section{INTRODUCTION}

Investigation of open channel flows is very important for a wide range of applications, including restoration and enhancement of river aquatic systems. As a result, the scientific community has focused on providing further insights on the flow characteristics in vegetated channels. Vegetation may be submerged or emerged, rigid or flexible with high or low density. For the case of rigid vegetation, the hydraulic behaviour of the channel is similar to the behaviour of a channel with macro-roughness which could be caused by the presence of geometrical elements (e.g. cylinders, cubes). For the case of flexible vegetation, both the flexibility of the vegetation and the 
hydrodynamics of the flow contribute to the generation of several formations such as erect, gently swaying, and prone. In a first approach, Kouwen and Unny (1973) developed a method to estimate the roughness for flow over submerged and flexible grass. Based on laboratory experiments, the authors concluded that the hydraulic behaviour using flexible plastic strips of grass is similar to that of a natural grass like vegetation. Mendoza and Zhou (1992) and Zhou and Mendoza (1993) were the first to present analytical results for the characteristics of turbulent flow above porous bed and the distribution of velocity within the porous layer respectively. In a similar study, Prinos et al. (2003) presented experimental and computational results for turbulent flow above and within a porous medium. The latter was simulated with a bundle of cylindrical rods. Experimental results from the above study were used by Chan et al. (2007) to validate a numerical model, based on macroscopic flow characteristics.

Stephan and Gutknecht (2002) investigated the resistance of submerged flexible aquatic vegetation on flow, and in particular the flow resistance of the natural macrophytes used by means of equivalent sand roughness. Results showed that the latter as well as the zero plane displacement of the logarithmic velocity profile were of the same order of magnitude as the mean deflected plant height and increased with increasing plant height. Wilson et al. (2003) experimentally investigated the effect of flexible vegetation on open channel flow. Two different forms of vegetation were used: a) flexible rods (strips) of constant height and b) the same rods with a frond foliage attached. An Acoustic Doppler Velocimeter was used to measure the velocity and turbulent characteristics. Results showed that in the case of foliage, the mean velocities are decreased significantly compared to the case without foliage. This suggests that regions which are prone to scour and erosion, microphysics with foliage may provide better protection relative to their non-foliage counterparts.

Jarvela (2005) investigated the flow structure above flexible vegetation (i.e. wheat). Velocity and turbulent characteristics were measured with a 3D Acoustic Doppler Velocimeter. Results showed that the flow above wheat follows a logarithmic law. The maximum values of the turbulence intensity and shear stress were found approximately at the level of the maximum observed deflected plant height. Carollo et al. (2005) conducted experiments in a straight flume having a bed covered with grass like vegetation in order to analyse flow resistance for flexible submerged elements. The authors concluded that a flow resistance equation, linking the friction factor with the shear Reynolds number, the depth-vegetation height ratio and the inflection degree can be established. Bigillon et al. (2006) experimentally investigated the turbulent characteristics of open-channel flows under transitionally-rough wall conditions. Vertical distributions of the velocity, turbulent intensities and vertical flux of turbulent kinetic energy were investigated using a PIV over a transitionally-rough fixed bed. Results were further compared with those obtained for smooth, rough and transitionally-rough walls. The authors conclude that the PIV technique can be applied successfully to investigate turbulent open channel flow over rough bed. In a similar study, Keramaris and Prinos (2009) investigated experimentally the characteristics of turbulent flow in open channel with porous bed. Measurements of velocity were acquired with the use of a hot-film anemometry. Results showed that the velocities above the porous region are much lower than the respective ones for flow over an impermeable bed. This is due to the turbulent shear stress and the penetration of turbulence in the porous region, which reduce the mean velocities above the porous region. More recently, Roussinova et al. (2010) carried out PIV measurements of the instantaneous velocity fields in a smooth open channel flow (Reynolds number was 21000 and the maximum velocity was $0.19 \mathrm{~m} \mathrm{~s}^{-1}$ ).

In the present work, the characteristics of turbulent flow in an open channel are studied experimentally using Particle Image Velocimetry (PIV). Twenty four experiments are carried out for both impermeable and permeable beds. Two grass-like vegetation types of different height ( 2 and 6 $\mathrm{cm}$ ) are used to represent permeable beds. Velocities are measured above the vegetation at different heights using a PIV system. The paper is organised as follows. Experimental procedure and methodology are introduced in Section 2, where we present the PIV method. Section 3 presents results consisting of velocity profiles based on permeable (using two different vegetation heights) and impermeable beds. Finally, Section 4 states the conclusions. 


\section{EXPERIMENTAL PROCEDURE AND MEASUREMENTS}

In total, 24 experiments were conducted in the laboratory of Hydraulics in the department of Civil Infrastructure Engineering of Alexander Technological Educational Institute of Thessaloniki, Greece. The channel has a length of $6.5 \mathrm{~m}$, width of $7.5 \mathrm{~cm}$ and height of $25 \mathrm{~cm}$. The vegetation was attached to a $2 \mathrm{~cm}$ thick wood, so that it remains fixed on the bed during the experiments. Hydraulic characteristics were measured at four different flow depths over the vegetation ( $h$ '; 5, 7, 9, $11 \mathrm{~cm}$ for the vegetation with $2 \mathrm{~cm}$ height and 1.5, 3, 5 and $7 \mathrm{~cm}$ for the vegetation with $6 \mathrm{~cm}$ height) and for three different discharges $\left(0.735,0.845\right.$ and $\left.0.970 \mathrm{~L} \mathrm{~s}^{-1}\right)$. The blades were made from plastic. The geometrical characteristics of the flow are presented in Figure 1.

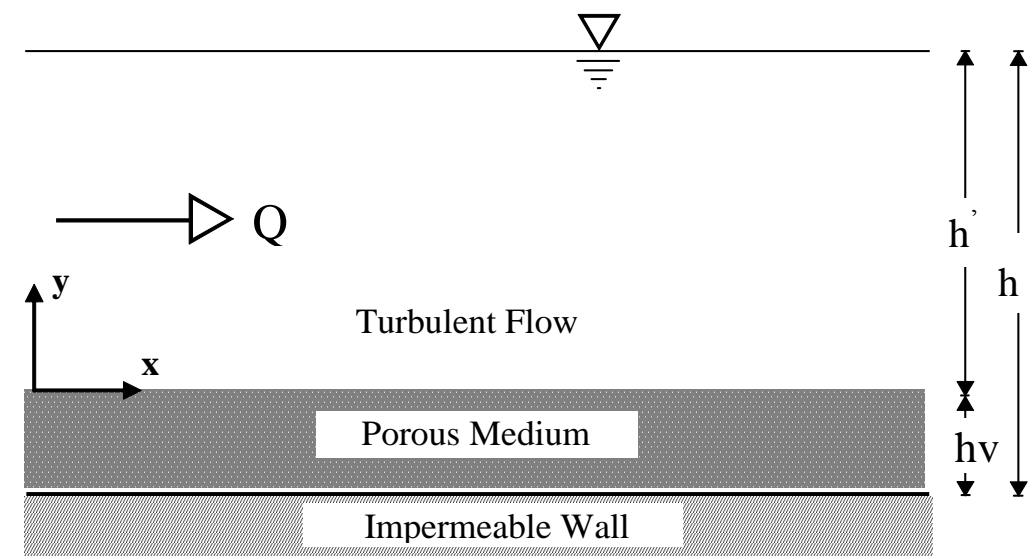

Figure 1. Geometrical characteristics of the flow

Table 1. Characteristics of the experiments

\begin{tabular}{l|c|c|c|c|c|c|c|c|c|c|c|c|c|}
\hline $\begin{array}{l}\text { Discharge } \\
\text { Q (lt/s) }\end{array}$ & \multicolumn{5}{|c|}{0.735} & \multicolumn{4}{|c|}{0.845} & \multicolumn{3}{|c|}{0.970} \\
\hline $\begin{array}{l}\text { Total flow depth } \\
\mathrm{h}(\mathrm{cm})\end{array}$ & 7 & 9 & 11 & 13 & 7 & 9 & 11 & 13 & 7 & 9 & 11 & 13 \\
\hline $\begin{array}{l}\text { Height of } \\
\text { vegetation } \\
\mathrm{h}_{\mathrm{v}} \text { (cm) }\end{array}$ & \multicolumn{3}{|c|}{$2[6]$} & & & $2[6]$ & & & $2[6]$ \\
\hline $\begin{array}{l}\text { Flow depth over } \\
\text { vegetation } \\
\mathrm{h}^{\prime}(\mathrm{cm})\end{array}$ & $5[1]$ & $7[3]$ & $9[5]$ & $11[7]$ & $5[1]$ & $7[3]$ & $9[5]$ & $11[7]$ & $5[1]$ & $7[3]$ & $9[5]$ & $11[7]$ \\
\hline
\end{tabular}

The morphology of the vegetation is illustrated in Photograph 1, and the characteristics of the experiments are presented in Table 1. These conditions are typical of flows encountered in sediment transport problems (in reality these conditions are equivalent to rivers of $1 \mathrm{~m}$ depth and $0.67 \mathrm{~m} \mathrm{~s}^{-1}$ mean velocity; this dynamic similarity can easily be estimated taking for granted that the Froude number is the same in reality and the experiment).
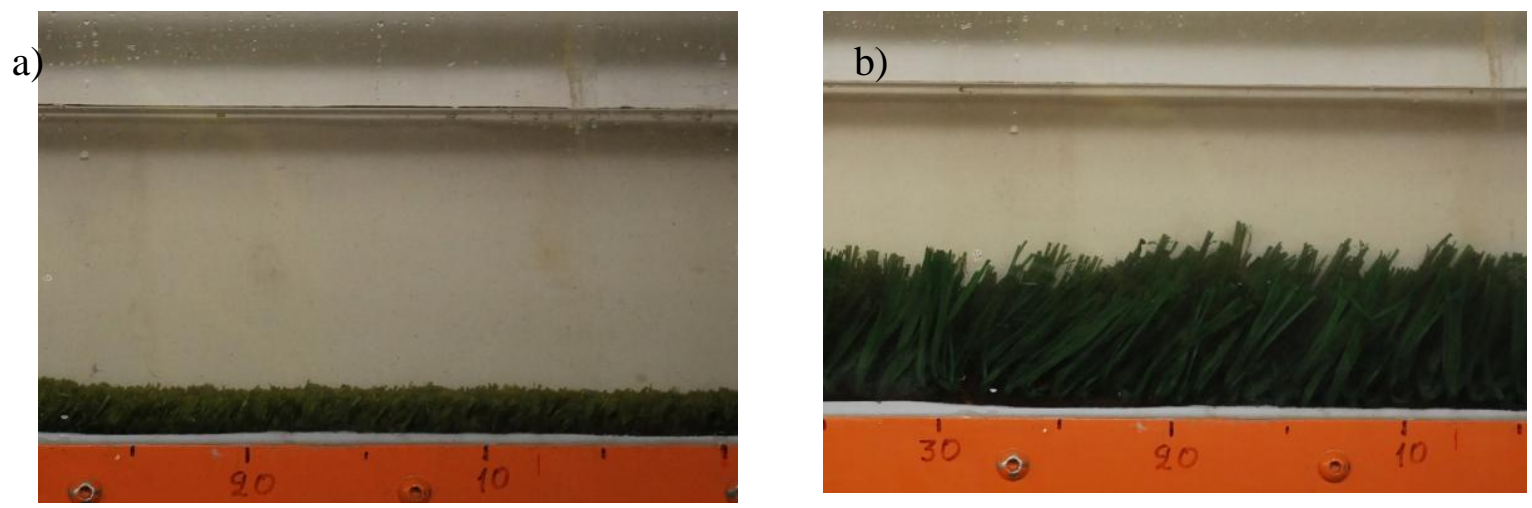

Photograph 1. Vegetation with: a) $2 \mathrm{~cm}$, and b) $6 \mathrm{~cm}$ height 
Measurements of velocity were taken for horizontal channel slope. PIV is an optical method of fluid visualisation and is used to obtain instantaneous velocity measurements and related properties in fluids (Figure 2). The fluid is seeded with tracer particles which, for the purposes of PIV, are generally assumed to faithfully follow the flow dynamics (Wereley and Meinhart, 2010). The motion of the seeding particles is used to calculate the velocity profile of the flow. Other techniques used to measure flows are Laser Doppler velocimetry and Hot-wire anemometry. The main difference between PIV and those techniques is that the former produces two dimensional vector fields, while the other techniques measure the velocity at a point. PIVs use the particle concentration method to identify individual particles in an image and follow their flow; however, tracking particles between images is not always a straightforward task. Individual particles could be "followed" when the particle concentration is low, a method called particle tracking velocimetry, whereas laser speckle velocimetry is used for cases where the particle concentration is high (Raffel et al., 2007). In this study, PIV was used to measure the velocity distribution, turbulence intensity and Reynolds stress.
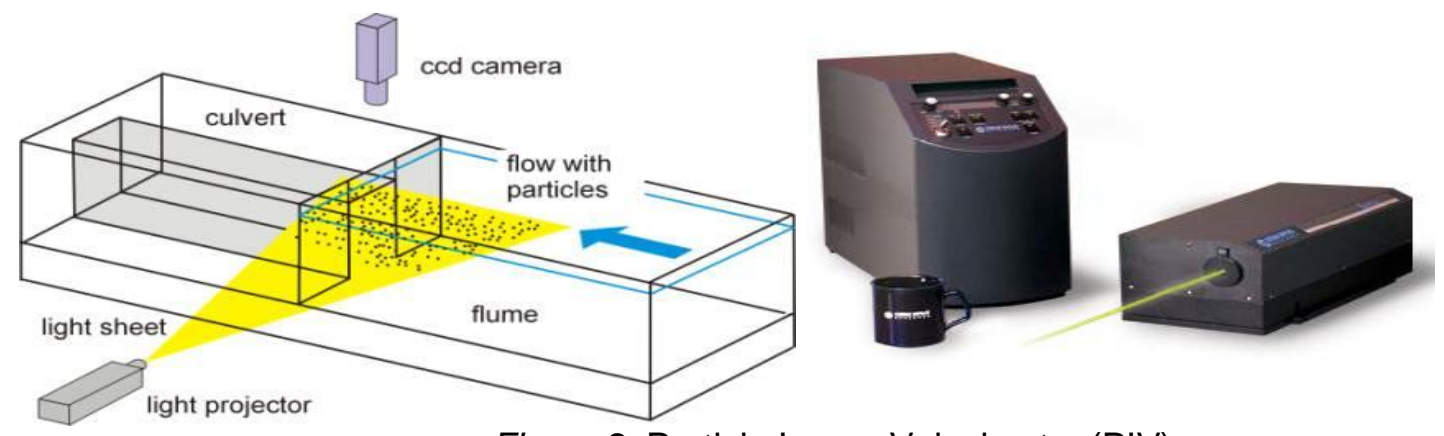

Figure 2. Particle Image Velocimetry (PIV)

The measurements were conducted at a $4 \mathrm{~m}$ distance from the channel's entrance and above the top of the vegetation, where the flow is considered fully developed. The full development of the flow was evaluated comparing the velocity distributions above the vegetation in two vertical sections with a 60 $\mathrm{cm}$ separation distance. The uniformity of the flow was checked measuring the flow depth with point gauges at two cross-sections ( $4 \mathrm{~m}$ between the two sections). The desirable flow depth in the downstream section could be controlled using a weir at the channel's outlet. The error of the measured flow depth with the point gauge was $\pm 0.1 \mathrm{~mm}$. The total discharge was measured at the channel's outlet using a triangular tank. The effects of lateral walls $(7.5 \mathrm{~cm})$ on the flow, $\mathrm{h} / \mathrm{s}^{\prime}$ on velocity distribution, and $\mathrm{h} / \mathrm{h}$ ' on channel discharge capacity were also investigated.

\section{ANALYSIS OF RESULTS}

Figure 3 illustrates the velocity field $\left(12 \times 10 \mathrm{~cm}^{2}\right)$ in the vertical level against the axis of the channel for different bed types. The $2 \mathrm{D}$ vector consisting of the velocity values has a $3 \mathrm{~mm}$ thickness. The color bar shows the velocity $\left(\mathrm{m} \mathrm{sec}^{-1}\right)$ at each grid. Figure $3 \mathrm{a}-3 \mathrm{c}$ highlight the velocity reduction, particularly close to the bed area, at a height of 2 and $6 \mathrm{~cm}$.

We calculated the mean velocity in the vertical level, and hence the velocity profiles, using each pair of photos for each experiment and control area. For instance, Figure $3 \mathrm{~b}$ shows the control area with approximately $2 \mathrm{~cm}$ width since the remaining area has been identified with noise. As known, the velocity profiles are characterized by a linear and a logarithmic area. A curve can be identified in the linear area to describe the velocity $(U)$ as a function of the distance from the bed $(y)$. The coefficient $y$ multiplied by the dynamic viscosity coefficient gives the value of the wall shear stress $\mathrm{T}_{0}$. This specifies the flow in each flow condition. For instance, Figure $3 d$ shows the velocity profile $(Q$ is $0.735 \mathrm{~L} \mathrm{~s}^{-1}, 2 \mathrm{~cm}$ vegetation height and $7 \mathrm{~cm}$ flow depth over vegetation) and the relationship between velocity and depth in the linear zone. 

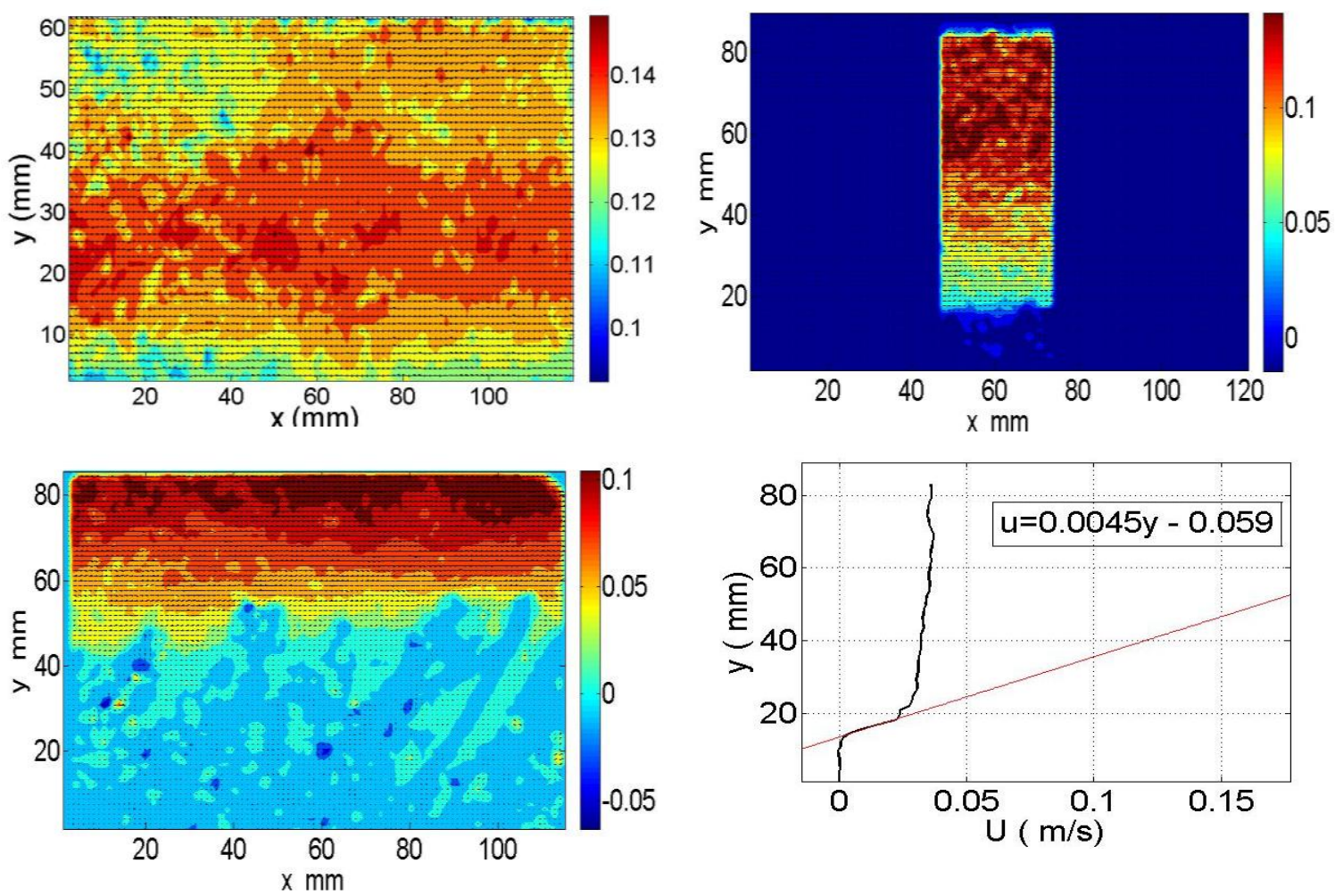

Figure 3. Field velocity over: a) impermeable bed, b) $2 \mathrm{~cm}$, and c) $6 \mathrm{~cm}$ vegetation height. Figure 3d illustrates the velocity profile for discharge $0.735 \mathrm{~L} \mathrm{~s}^{-1}, 2 \mathrm{~cm}$ vegetation height and $7 \mathrm{~cm}$ flow depth over vegetation. The red line shows the relationship between velocity and depth in the linear zone.

The current analysis aims to identify the relationship between discharge, total flow depth, vegetation height, and velocity distribution. Figure 4 illustrates the impact of water depth $(5,7,9$ and $11 \mathrm{~cm})$ on the velocity profile; hence vegetation height and discharge are kept constant and equal to $2 \mathrm{~cm}$ and $0.735 \mathrm{~L} \mathrm{~s}^{-1}$ respectively. Overall, velocity decreases when the total water depth increases; and hence the $h / h$ ' ratio. It is important to note that the velocity slope in the linear zone decreases as the water depth over vegetation increases; hence the shear stresses increase. In addition, results show that the difference in the velocity profiles varies linearly in the turbulent zone.

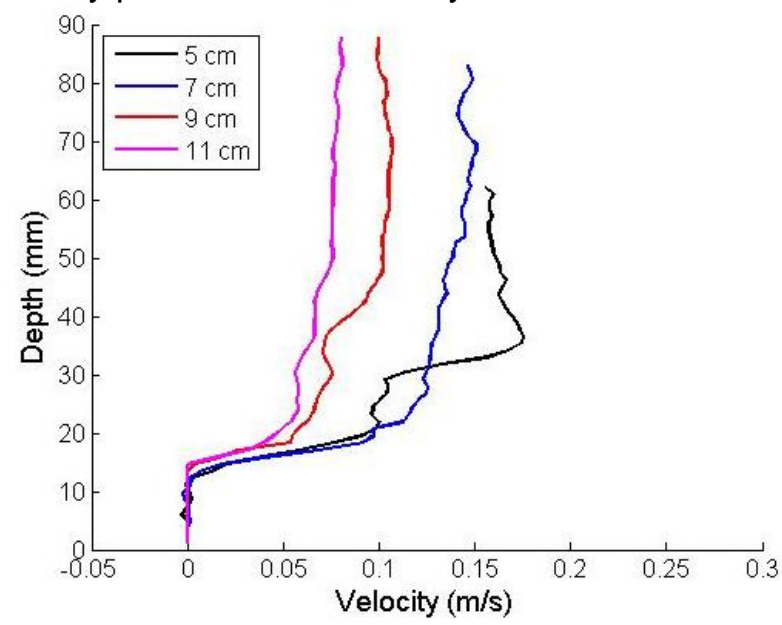

Figure 4. The effect of total water depth on the velocity distribution. Vegetation height and discharge are constant and equal to $2 \mathrm{~cm}$ and $0.735 \mathrm{~L} \mathrm{~s}^{-1}$ respectively 


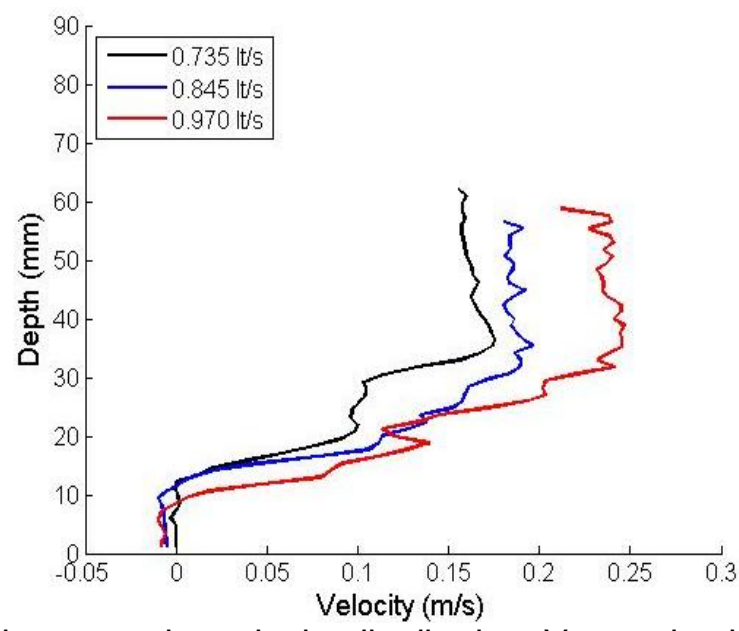

Figure 5. The effect of discharge on the velocity distribution. Vegetation height and water depth over the vegetation are constant and equal to 2 and $5 \mathrm{~cm}$ respectively
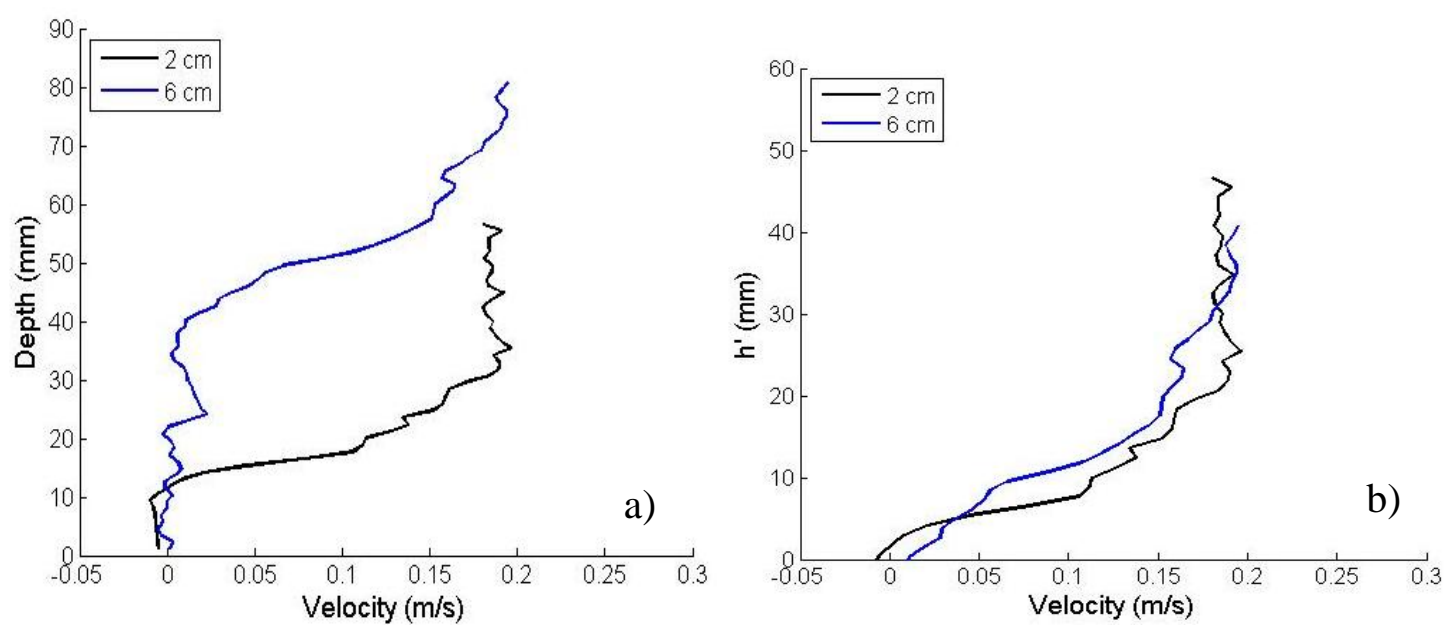

Figure 6. The effect of vegetation height on the velocity distribution: a) total flow depth, and b) flow depth over vegetation. Water depth over the vegetation and discharge are constant ( $5 \mathrm{~cm}$ and $0.845 \mathrm{~L} \mathrm{~s}^{-1}$ respectively)

The effect of discharge on the velocity distribution is illustrated in Figure 5. As expected, for a fixed vegetation height and total water depth, the velocity increases as the discharge increases. The difference in the velocity is more obvious at higher heights $(>30 \mathrm{~mm})$, where the effect of vegetation is less obvious. Figure 6 highlights the effect of vegetation height on the velocity distribution. Results show that velocities are reduced as the vegetation height increases. The velocity slope in the linear zone is greater using short rather than high vegetation under the same discharge conditions (see Figure $6 \mathrm{~b}$ ). In the current analysis, moving from a vegetation height of 2 to $6 \mathrm{~cm}$ can significantly reduce the velocity (close to $0 \mathrm{~m} \mathrm{~s}^{-1}$ ).

Figure 7 shows the velocity distribution above the vegetation for $h_{v}=2 c m\left(h / h_{v}=5.5\right.$ and 3.5) and $h_{\mathrm{v}}=6 \mathrm{~cm}\left(\mathrm{~h} / \mathrm{h}_{\mathrm{v}}=2.17\right.$ and 1.83) and for a constant discharge $\left(0.735 \mathrm{~L} \mathrm{~s}^{-1}\right)$. The logarithmic law for flow over a solid, impermeable bed with depth $\mathrm{h}$ is also illustrated. We use dimensionless velocities using the friction velocity $U_{*}\left(U_{*}=\sqrt{\tau_{0} / \rho}\right.$, where $\mathrm{T}_{0}$ is shear stress $\left(\tau_{0}=\mu \frac{\partial u}{\partial y}\right), \mu$ is dynamic viscosity and $\rho$ is the water density) and the distance from the interface $y$ with the ratio $U_{*} / v$. This normalisation allows us to evaluate the applicability of the logarithmic law for these conditions. Velocities are below the logarithmic law line which indicates that velocities above vegetation are reduced in comparison with velocities over an impermeable bed. In particular, the velocities are reduced with decreasing $h / h_{v}$ ratio due to the greater influence of the vegetation on the flow above it. 
Finally, Figure 7 (using both 2 and $6 \mathrm{~cm}$ vegetation height) highlights the reduction in the discharge capacity of open vegetated channels with low $h / h_{v}$ values.
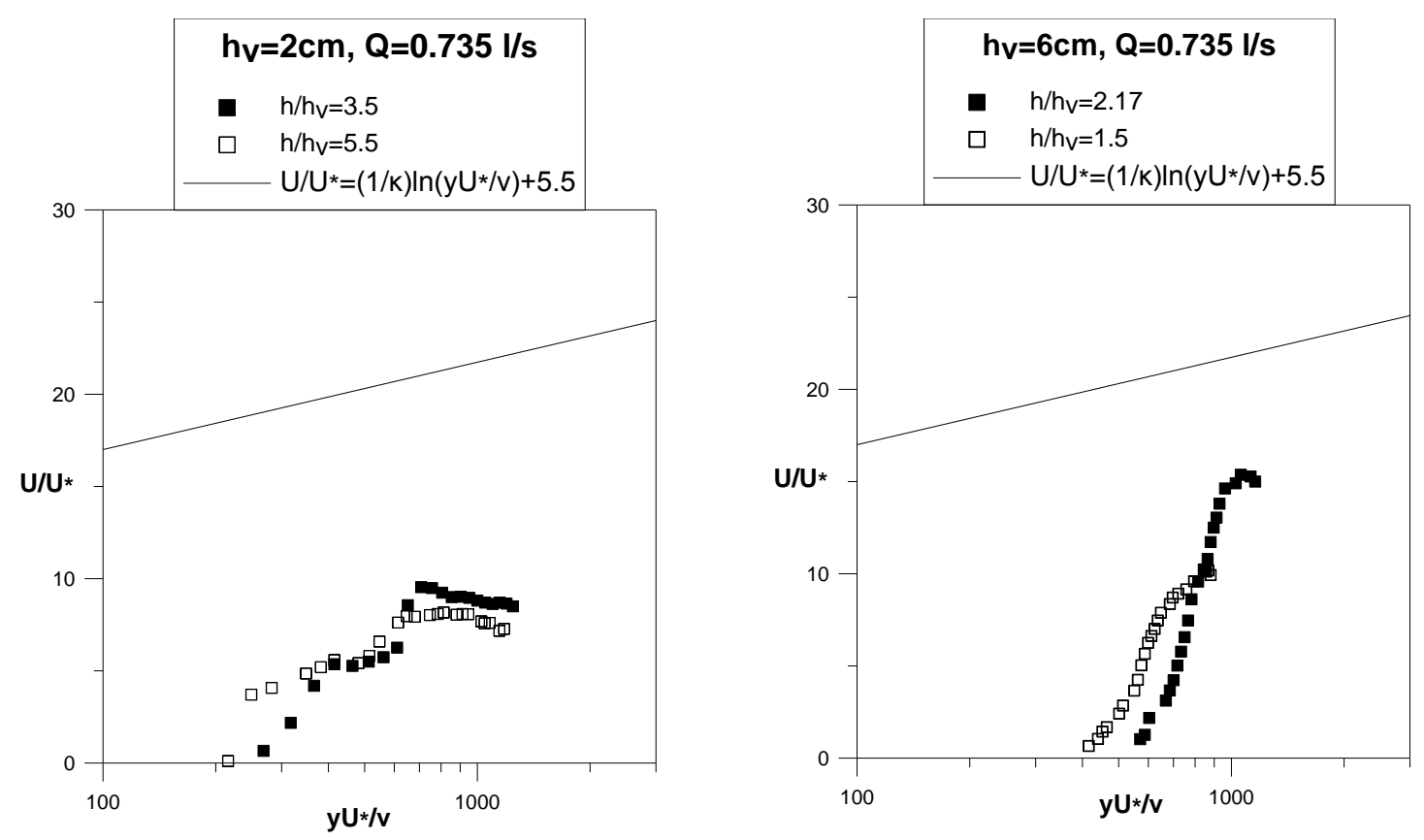

Figure 7. Dimensionless velocity ( $\left.h / h^{\prime}\right)$ distribution using constant discharge $\left(0.735 \mathrm{~L} \mathrm{~s}^{-1}\right)$ and vegetation depth ( $h_{v}$ ) equal to: a) $2 \mathrm{~cm}$, and b) $6 \mathrm{~cm}$

\section{CONCLUSIONS}

This paper investigated experimentally the effect of submerged vegetation on the characteristics of open channel flow. In particular, we focused on the impact of vegetation height and discharge on the velocity profile, and we derived the following conclusions:

- For the same vegetation height and the same discharge, the increase of flow depth over the vegetation reduces the velocity.

- For the same vegetation height and the same flow depth, the increase of discharge increases the velocity.

- The velocity over the vegetation region is reduced when the vegetation height increased.

- Approximately zero velocity is observed between 6 and $3 \mathrm{~cm}$, and 2 and $1 \mathrm{~cm}$ for vegetation height of 6 and $2 \mathrm{~cm}$ respectively. This means that $50 \%$ of vegetation behaves as an impermeable bed.

- The velocities are reduced with decreasing $h / h_{v}$ ratio due to the greater influence of the vegetation on the flow above it.

Experiments will continue using several vegetation heights and total water depths; particularly focusing on water depths higher than $11 \mathrm{~cm}$.

\section{ACKNOWLEDGEMENTS}

The authors would like to express their sincere gratitude to Dr Eirini Spentza for her constructive comments and detailed suggestions that have resulted in an improved manuscript.

\section{REFERENCES}

1. Bigillon F., Nino Y. and Garcia M. (2006), Measurements of turbulence characteristics in an openchannel flow over a transitionally-rough bed using particle image velocimetry, Experiments in Fluids, 41(6), 857-867.

2. Carollo F.G., Ferro V. and Termini D. (2005), Flow resistance law in channels with flexible submerged vegetation, Journal of Hydraulic Engineering, 131(7), 554-564. 
3. Chan H.C., Leu J.M., Lai C.J. and Yafei J. (2007), Turbulent flow over a channel with fluid-saturated porous bed, Journal of Hydraulic Engineering, 133(6), 610-617.

4. Jarvela J. (2005), Effect of submerged flexible vegetation on flow structure and resistance, Journal of Hydrology, 307, 233-241.

5. Keramaris E. and Prinos P. (2009), Hot-Film Measurements of Turbulent Flow in an Open Channel with a Permeable Bed, Hydrotechnica, 18-19: 3-20.

6. Kouwen N. and Unny T.E. (1973), Flexible roughness in open channels. Journal of the Hydraulics Division, 99(5), 713-728.

7. Mendoza C. and Zhou D. (1992), Effects of Porous Bed on Turbulent Streamflow Above Bed, Journal of Hydraulic Engineering, 118, 1222-1239.

8. Prinos P., Sofialidis D. and Keramaris E. (2003), Turbulent flow over and within a porous bed, Journal of Hydraulic Engineering, 129, 720-733.

9. Raffel M., Willert C., Wereley S. and Kompenhans J. (2007), Particle Image Velocimetry: A Practical Guide, Springer-Verlag.

10. Roussinova V., Shinneeb A-M. and Balachandar R. (2010), Investigations of fluid structures in a smooth open-channel flow using proper orthogonal decomposition, Journal of Hydraulic Engineering, 136(3), 143-154.

11. Stephan U. and Gutknecht D. (2002), Hydraulic resistance of submerged flexible vegetation, Journal of Hydrology, 269(1/2), 27-43.

12. Wereley S.T. and Meinhart C.D. (2010), Recent advantages in micro-particle image velocimetry, Annual Review of Fluid Mechanics, 42(1), 557-576.

13. Wilson C.A.M.E, Stoesser T., Bates P.D. and Batemann Pinzen A. (2003), Open channel flow through different forms of submerged flexible vegetation, Journal of Hydraulic Engineering, 129(11), 847-853.

14. Zhou D. and Mendoza C. (1993), Flow through Porous Bed of Turbulent Stream, Journal of Engineering Mechanics, 119(2), 365-383. 